\title{
Volumetric Software Tools Using Artificial Intelligence in Evaluation of Regional Gray and White Matter Volume Changes in Patients Having Migraine Without Aura
}

\author{
AHMAD EL-MORSY, M.D.*; SAHER EBRAHIM TAMAN, M.D.*; TAMER M BELAL, M.D.** and \\ MONA MAHMOUD ZAKY, M.D.* \\ The Departments of Diagnostic Radiology* and Neurology**, Mansoura Faculty of Medicine, Mansoura University, \\ Mansoura, Egypt
}

\begin{abstract}
Background: Migraine is a predominant headache that features pulsating pain that is mostly unilaterally provoked by regular physical activity and is accompaniedby nausea and/or photophobia and phonophobia. A range of autonomic, cognitive, and emotional disturbances may accompany migraine. High prevalence and elevated socioeconomic and personal effect have been recorded by epidemiological studies. Migraine has an incidence of $14 \%$ in the overall population for one year. The Global Burden of Disease Survey ranked it as the sixth largest worldwide cause of disability.
\end{abstract}

Aim of Study: The aim of this study is to assess the role of volumetric software tools using artificial intelligence in evaluation of regional gray and white matter volume changes in patients having migraine without aura.

Patients and Methods: We enrolled in this prospective study 20 patients, age ranged from 13 to 52 years old (mean $=33.65$ years, $\mathrm{SD}=10.68), 1$ male and 19 female patients $(5 \%$ and $95 \%$ respectively). Ten patients $(50 \%)$ suffering from right side migraine, $8(40 \%)$ from left side and two patients (10\%) suffering bilaterally. 3D T1-weighted MRI images with dedicated parameters were uploaded to NeuroQuant software which is FDA approved software for segmental brain volumetric studies. Automated reports for volume changes were obtained.

Results: Focal hypertrophy was observed in 14 (70\%) patients for cerebellar white matter, $11(55 \%)$ patients for cingulate gyrus, $10(50 \%)$ patients for nucleus accumabens, $10(50 \%)$ patients for Hippocampus, $8(40 \%)$ patients for thalamus, $8(40 \%)$ patients for isthmus cingulate, $7(35 \%)$ patients for posterior superior temporal sulcus, anterior cingulate, para hippocampaleach \& $6(30 \%)$ patients for cerebral white matter and ventral diencephalon. Less percentage was noted for focal atrophy, 9 (45\%) patients for medial orbitofrontal gyrus, 7 (35\%) patients for posterior superior temporal sulcus \& 4 (20\%) patients for ventricles.

Conclusion: Patients having migraine without aura show gray and white matter volume changes in different cerebral

Correspondence to: Dr. Ahmad El-Morsy,

E-Mail: dr.a.elmorsy@gmail.com and cerebellar areas that could be detected by MRI and improved by using artificial intelligence software programs for accurate, fast, automated volume changes detection.

Key Words: MRI - Migraine - Gray matter - White matter - NeuroQuant.

\section{Introduction}

MIGRAINE is a predominant headache that features pulsating pain that is mostly unilaterally provoked by regular physical activity and is accompaniedby nausea and/or photophobia and phonophobia [1]. A range of autonomic, cognitive, and emotional disturbances may accompany migraine [2]. High prevalence and elevated socioeconomic and personal effect have been recorded by epidemiological studies. Migraine has an incidence of $14 \%$ in the overall population for one year [3]. The Global Burden of Disease Survey ranked it as the sixth largest worldwide cause of disability [4]

Genetic and environmental factors are directly related to migraine attack initiation. Migraine genomeassociation studies have shown that genetics are committed in migraine [5]. Migraine is obviously associated with environmental variables as stress, climate, hormonal variations, sleep disorders, skipping meals and sensory problem [6]. Whatever the cause is, during migraine imaging led to a change from migraine pathophysiology vascular hypotheses to the theories of the neurovascular or Central Nervous System (CNS). MRI is an invasive less procedure that can determine the morphological

\footnotetext{
List of Abbreviations:

MRI : Magnetic Resonance Imaging.

3D : Three Dimension.

CNS : Central Nervous System.
} 
basis of neurological disease and investigate functional-structural associations [7].

Volumetric MR imaging technology was available in research and clinical environments for more than 20 years. During this time radiology centers used their imaging parameters and manually evaluated the resulting images. This made the clinical application of this technology not reliable because it was subjective and inconsistent from patient to patient and scanner to scanner [8,9].

The introduction of large multi-institution research studies started the streaming of acquisition protocols like the software used in our study that provided consistent, anatomical and operator independent measures of the volumes of different brain structures. Different studies have been already done for evaluation of this software which is FDA approved and the results were comparable in accuracy, faster and more precise than manual segmentation [10-14].

Migraine is classified as a heterogeneous disease and is proposed to coexist with degenerative and maladaptive plasticity [15]. Imaging studies found that migraine is associated with structural alterations that affect gray and white matter $[16,17]$ Migraine was associated with a common core collection of decreased volume of gray matter in variable areas in cerebellar hemispheres on magnetic resonance imaging $[\mathbf{5 , 1 1}]$

\section{Patients and Methods}

\section{Patient:}

This prospective study was permitted by Institutional Review Board (IRB). Informed consents were obtained from all patients before MRI examination. Patients with clinical suspicion of migraine headache without aura based on patient complaint were clinically examined in order to exclude any other causes of unilateral headache such as sinusitis, refractive disorders or referred dental pain. Patients with any MRI contraindications such as claustrophobic patients, patients with peacemakers or any other head and neck prothesis were excluded, as were other brain pathologies such as inflammatory lesions, tumors or demyelinating diseases. Finally, 20 patientshaving migraine without aura were included in this study with their age ranged from 13 to 52 years old (mean $=33.65$ years, $S D=10.68$ ). The study included 1 male and 19 female patients (5\% and $95 \%$ respectively), they were suffering from migraine for 1 to 25 years (mean $=10.5$ years, $\mathrm{SD}=7.92$ ) with frequency of attacks 2 to 6 times per month (mean=3.6/month, $\mathrm{SD}=1.38$ ), last attack before our MRI exam was 0.43 to 4 weeks (mean= 1.54 weeks, $\mathrm{SD}=1.05)$. Ten patients $(50 \%)$ suffering from right side migraine, 8 (40\%) from left side and two patients (10\%) suffering bilaterally.

This study was conducted at the Department of Radiology, Faculty of Medicine, Mansoura University from March 2019-March 2020.

\section{Magnetic resonance imaging:}

All patients included in this study underwent conventional MR imaging using a 1.5-T MR imaging scanner (Ingenia, Philips) with 20 channel neurovascular head and neck coil. First conventional MRI scanning with matrix about 80 X 80 with slice thickness $5 \mathrm{~mm}$ including axial, sagittal and coronal $\mathrm{T} 1 \mathrm{WI}(\mathrm{TR}=600 \mathrm{~ms}, \mathrm{TE}=25 \mathrm{~ms}) \& \mathrm{~T} 2 \mathrm{WI}$ (TR=6000ms, TE $90=\mathrm{ms})$. Then a 3D sagittal T $1 \mathrm{WI}$ images were taken according to the recommended NeuroQuant sittings for Philips 1.5 Tesla machine (Table 1).

Table (1): Showing recommended NeuroQuant sittings (for Sagittal 3D T1WI) Philips 1.5 Tesla machine.

\begin{tabular}{ll}
\hline Field strength & \multicolumn{1}{c}{$1.5 \mathrm{~T}$} \\
\hline FOV & $240-256 \mathrm{~mm}$ \\
RFOV & $100 \%$ \\
Matrix scan & 192 \\
Scan percentage & $100 \%$ \\
Stacks & 1 \\
Slices & $160-170$ \\
Slice thickness & $1.2 \mathrm{~mm}$ \\
Slice orientation & Sagittal \\
Scan mode & $3 \mathrm{D}$ \\
Technique & FFE \\
Contrast enhancement & T1 \\
Fast imaging mode & TFE \\
TFE shot interval & $2300 \mathrm{~ms}$ \\
ECHOES & 1 \\
TE & $4 \mathrm{~ms}$ \\
Flip angle & 8 deg \\
TR & Shortest \\
TFE prepulse delay/T1 & $1000 \mathrm{~ms}$ \\
Water fat shift & Maximum \\
Gradient mode & Default \\
Clear & On \\
Parallel imaging method & N/A \\
Maximum parallel imaging acceleration factor & N/A \\
\hline & \\
\hline & \\
\hline &
\end{tabular}

\section{Image analysis:}

On secondary workstation (extended MR Workspace 2.6.3.5, Philips medical systems Nederland B.V) The DICOM images were transferred, after revision of the images for any possible exclusion pathologies and for any artefacts, finally the 3D T1 weighted images were uploaded online to the NeuroQuant software from CORTECHS labsresearch mode-using triage brain atrophy report 
for approximately 44 areas of gray and white matters of both cerebral hemispheres. The software automatically detects and highlights atrophied and hypertrophied areas in separate regions considering patient age and sex with respectively red and blue colors Fig. (1).

\section{NeuroQuant ${ }^{\circledR}$ \\ Triage Brain Atrophy Report}

\section{MORPHOMETRY RESULTS}
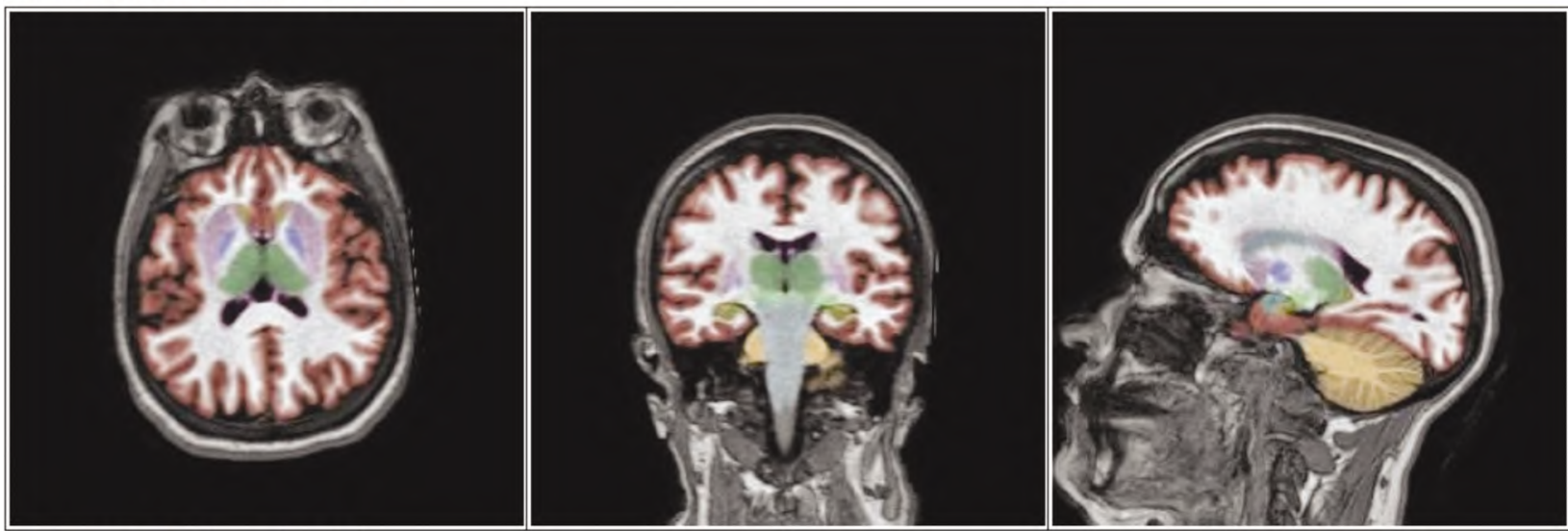

\begin{tabular}{|c|c|}
\hline $\begin{array}{c}\text { Intracranial Volume (ICV) } \\
\left(\mathrm{cm}^{3}\right)\end{array}$ & ICV Percentile \\
\hline 1418.76 & 13 \\
\hline \multirow{2}{*}{ Total Volumes } & Percentiles \\
\hline & Right \\
\hline
\end{tabular}

\begin{tabular}{|c|c|c|c|}
\hline \multirow{2}{*}{ Cortical Brain Regions } & \multicolumn{3}{|c|}{ Percentiles } \\
\hline & Left & Right & Total \\
\hline Frontal Lobes & 7 & 9 & 8 \\
\hline Superior Frontal & 62 & 56 & 60 \\
\hline Middle Frontal & 10 & 17 & 10 \\
\hline Inferior Frontal & 6 & 2 & 2 \\
\hline Lateral Orbitofrontal & 1 & 20 & 2 \\
\hline Medial Orbitofrontal & 3 & 1 & 1 \\
\hline Paracentral & 44 & 29 & 37 \\
\hline Primary Motor & 19 & 26 & 18 \\
\hline Parietal Lobes & 26 & 41 & 33 \\
\hline Primary Sensory & 26 & 61 & 41 \\
\hline Medial Parietal & 17 & 28 & 20 \\
\hline Superior Parietal & 27 & 46 & 35 \\
\hline Inferior Parietal & 66 & 72 & 71 \\
\hline Supramarginal & 39 & 9 & 19 \\
\hline Occipital Lobes & 5 & 3 & 3 \\
\hline Medial Occipital & 6 & 7 & 6 \\
\hline Lateral Occipital & 12 & 7 & 6 \\
\hline Temporal Lobes & 11 & 10 & 10 \\
\hline $\begin{array}{l}\text { Transverse Temporal + } \\
\text { Superior Temporal }\end{array}$ & 1 & 3 & 1 \\
\hline \begin{tabular}{|l|} 
Posterior Superior \\
Temporal Sulcus \\
\end{tabular} & 56 & 89 & 83 \\
\hline Middle Temporal & 71 & 51 & 62 \\
\hline Inferior Temporal & 2 & 2 & 1 \\
\hline Fusiform & 2 & 2 & 1 \\
\hline Parahippocampal & 84 & 99 & 96 \\
\hline Entorhinal Cortex & 45 & 85 & 69 \\
\hline Temporal Pole & 66 & 23 & 42 \\
\hline Amygdala & 96 & 95 & 96 \\
\hline Hippocampus & 99 & 99 & 99 \\
\hline
\end{tabular}

\begin{tabular}{|l|c|c|c|}
\hline Cerebral White Matter & 88 & 93 & 91 \\
\hline Cortical Gray Matter & 7 & 8 & 8 \\
\hline Ventricles & 70 & 83 & 77 \\
\hline
\end{tabular}

Subcortical Structures

Cerebellar White Matter

Cerebellar Gray Matter

Brainstem

Thalamus

Ventral Diencephalon

Basal Ganglia

Putamen

Caudate

Nucleus Accumbens

Pallidum

Cingulate

Anterior Cingulate

Posterior Cinculate

Isthmus Cingulate

\begin{tabular}{|c|c|c|c|}
\hline & 49 & 52 & 50 \\
\hline & - & - & 82 \\
\hline & 97 & 99 & 99 \\
\hline & 90 & 92 & 92 \\
\hline & 87 & 92 & 90 \\
\hline & 77 & 74 & 77 \\
\hline & 68 & 27 & 46 \\
\hline & 43 & 44 & 44 \\
\hline & 46 & 10 & 20 \\
\hline & 27 & 7 & 10 \\
\hline
\end{tabular}

Hippocampus

Fig. (1): Output from NeuroQuant. For several brain areas on both sides with auto detection of atrophy or hypertrophy in relation to patient age and sex. 


\section{Statistical analysis:}

Data definition took the form of mean and Standard Deviation (SD). Data analysis was conducted using Version 20 (SPSS Inc., Chicago, Ill, USA) the statistical analysis of data will be done.

\section{Results}

As shown in (Table 2), hypertrophy was observed in $14(70 \%)$ patients for cerebellar white matter, $11(55 \%)$ patients for cingulate gyrus, 10
$(50 \%)$ patients for nucleus accumabens, $10(50 \%)$ patients for Hippocampus, $8(40 \%)$ patients for thalamus, 8 (40\%) patients for isthmus cingulate, $7(35 \%)$ patients for posterior superior temporal sulcus, anterior cingulate, Para hippocampal each, $6(30 \%)$ patients for cerebral white matter and ventral diencephalon, and other less percentage for different areas as shown in Fig. (2). Less percentage was noted for focal atrophy as shows in Fig. (3), 9 (45\%) patients for medial orbitofrontal gyrus, 7 (35\%) patients for posterior superior temporal sulcus \& 4 (20\%) patients for ventricles.

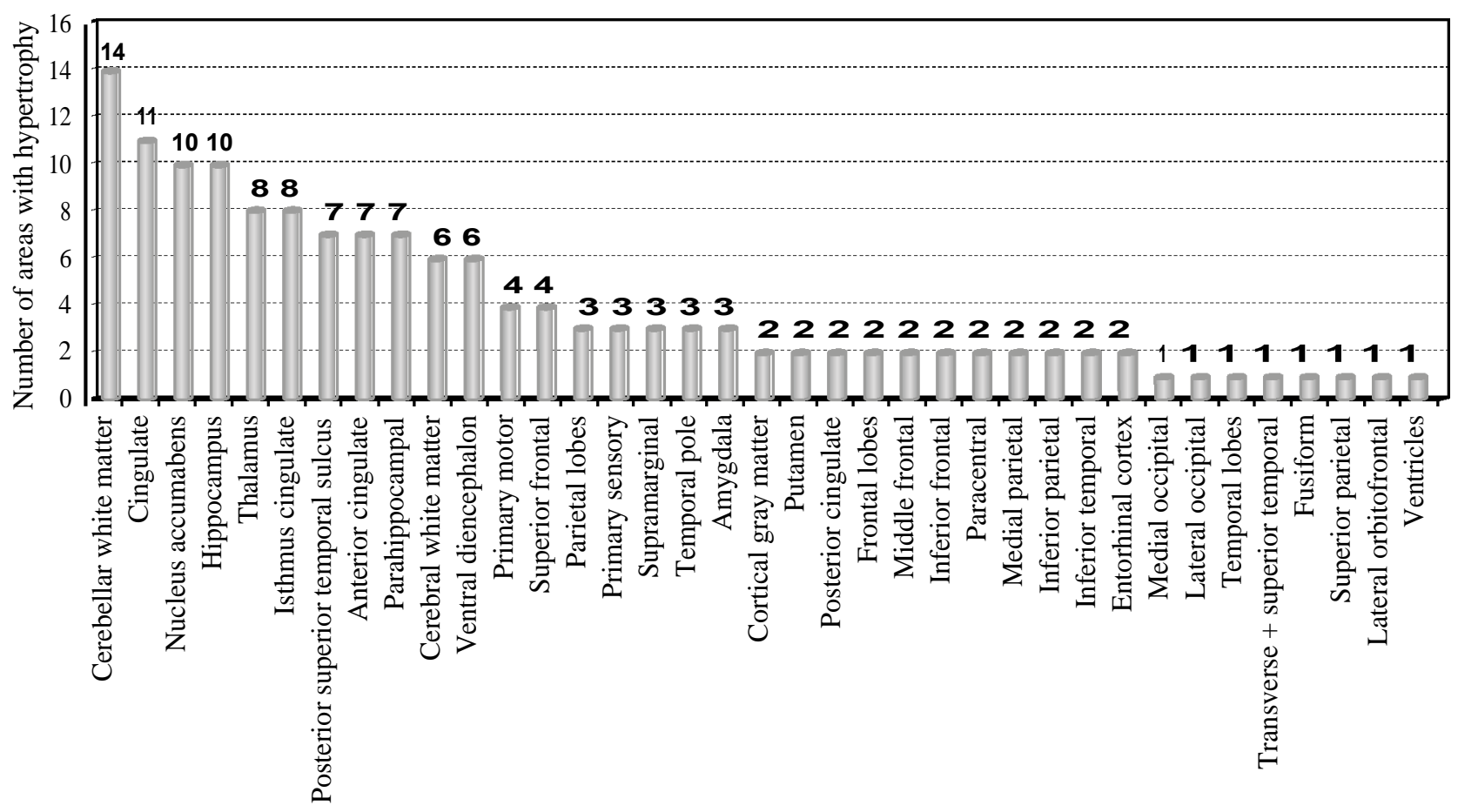

Fig. (2): Chart for number of brain areas with hypertrophy in migraine patients.

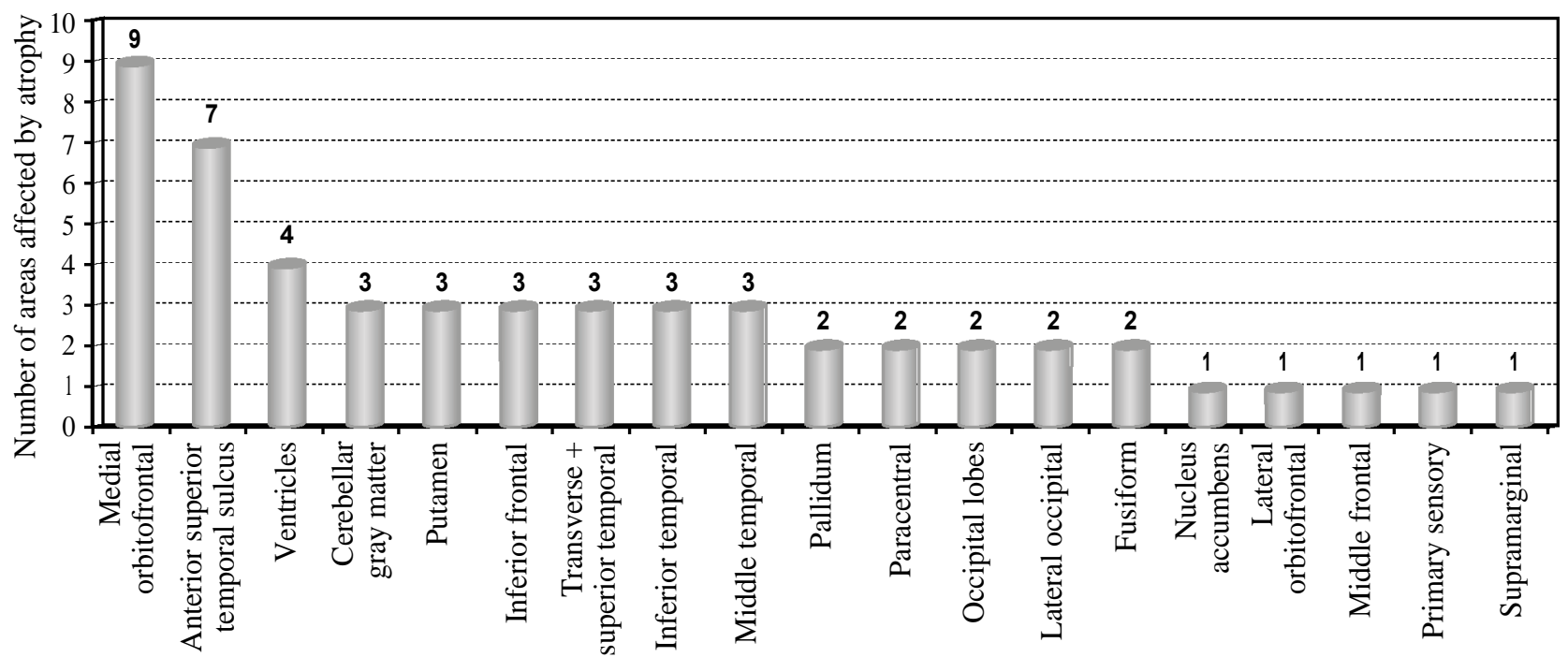

Fig. (3): Chart for number of brain areas with atrophy in migraine patients. 
Table (2): Showing several brain areas with related number and percentage of atrophy and hypertrophy.

\begin{tabular}{|c|c|c|c|c|}
\hline \multirow{3}{*}{ Affected area } & \multicolumn{4}{|c|}{$\begin{array}{c}\text { Number of examined } \\
\text { areas (40) }\end{array}$} \\
\hline & \multicolumn{2}{|c|}{ Hypertrophy } & \multicolumn{2}{|c|}{ Atrophy } \\
\hline & $\mathrm{N}$ & $\%$ & $\mathrm{~N}$ & $\%$ \\
\hline Cerebral white matter & 6 & 15.0 & 0 & 0.0 \\
\hline Cortical gray matter & 2 & 5.0 & 0 & 0.0 \\
\hline Ventricles & 1 & 2.5 & 4 & 10.0 \\
\hline Cerebellar white matter & 14 & 35.0 & 0 & 0.0 \\
\hline Cerebellar gray matter & 0 & 0.0 & 3 & 7.5 \\
\hline Brain stem & 0 & 0.0 & 0 & 0.0 \\
\hline Thalamus & 8 & 20.0 & 0 & 0.0 \\
\hline Ventral diencephalon & 6 & 15.0 & 0 & 0.0 \\
\hline Putamen & 2 & 5.0 & 3 & 7.5 \\
\hline Caudate & 0 & 0.0 & 0 & 0.0 \\
\hline Nucleus accumabens & 10 & 25.0 & 1 & 2.5 \\
\hline Pallidum & 0 & 0.0 & 2 & 5.0 \\
\hline Cingulate & 11 & 27.5 & 0 & 0.0 \\
\hline Anterior cingulate & 7 & 17.5 & 0 & 0.0 \\
\hline Posterior cingulate & 2 & 5.0 & 0 & 0.0 \\
\hline Isthmus cingulate & 8 & 20.0 & 0 & 0.0 \\
\hline Frontal lobes & 2 & 5.0 & 0 & 0.0 \\
\hline Superior frontal & 4 & 10.0 & 0 & 0.0 \\
\hline Middle frontal & 2 & 5.0 & 1 & 2.5 \\
\hline Inferior frontal & 2 & 5.0 & 3 & 7.5 \\
\hline Lateral orbitofrontal & 1 & 2.5 & 1 & 2.5 \\
\hline Medial orbitofrontal & 0 & 0.0 & 9 & 22.5 \\
\hline Paracentral & 2 & 5.0 & 2 & 5.0 \\
\hline Primary motor & 4 & 10.0 & 0 & 0.0 \\
\hline Parietal lobes & 3 & 7.5 & 0 & 0.0 \\
\hline Primary sensory & 3 & 7.5 & 1 & 2.5 \\
\hline Medial parietal & 2 & 5.0 & 0 & 0.0 \\
\hline Superior parietal & 1 & 2.5 & 0 & 0.0 \\
\hline Inferior parietal & 2 & 5.0 & 0 & 0.0 \\
\hline Supramarginal & 3 & 7.5 & 1 & 2.5 \\
\hline Occipital lobes & 0 & 0.0 & 2 & 5.0 \\
\hline Medial occipital & 1 & 2.5 & 0 & 0.0 \\
\hline Lateral occipital & 1 & 2.5 & 2 & 5.0 \\
\hline Temporal lobes & 1 & 2.5 & 0 & 0.0 \\
\hline Transverse + superior temporal & 1 & 2.5 & 3 & 7.5 \\
\hline Posterior superior temporal sulcus & 7 & 17.5 & 7 & 17.5 \\
\hline Middle temporal & 0 & 0.0 & 3 & 7.5 \\
\hline Inferior temporal & 2 & 5.0 & 3 & 7.5 \\
\hline Fusiform & 1 & 2.5 & 2 & 5.0 \\
\hline Parahippocampal & 7 & 17.5 & 0 & 0.0 \\
\hline Entorhinal cortex & 2 & 5.0 & 0 & 0.0 \\
\hline Temporal pole & 3 & 7.5 & 0 & 0.0 \\
\hline Amygdala & 3 & 7.5 & 0 & 0.0 \\
\hline Hippocampus & 10 & 25.0 & 0 & 0.0 \\
\hline
\end{tabular}

\section{Discussion}

Migraine is considered a heterogeneous disease with numerous imaging studies [11-14] revealing that it is linked to structural changes in the gray and white matter $[\mathbf{9 , 1 0 ]}$. Many of these studies demonstrated gray matter atrophy in pain network regions, explained by chronic stimulation and aging of these areas,accompanied by other painful con- ditions [22-25]. Other studies in migraine patients revealed gray matter hypertrophy [26,27], few studies assessed gray matter thickness demonstrated conflicting outcome [26,28-30]

In the current study we want to make benefit from using Artificial Intelligence dependent software in volumetric assessment of different brain structures in patients having migraine without aura. This is considered a pioneer study as the software we are using was used only in assessment of neurodegenerative disease like multiple sclerosis, posttraumatic brain atrophy, Dementia and epilepsy [10-14] ... but to our knowledge, this is the first time to use it in migraine without aura. We are hoping to open new research area in the field of diagnosis and follow-up of migraine headache after using different lines of therapy. This is will be strengthened by the fast, easy and accurate segmental quantitative assessment of multiple brain structures (gray and white matter) making the results of MR examination like blood test. Added to that, like other Artificial Intelligence dependent software, it can be integrated with PACS system making it easier to use with no delay. Also, the results of each report will be automatically compared to age and sex matched controls and to the patient's cranial volume which were already integrated within the software database, making the results more reliable.

Throughout our study, the areas of the brain hypertrophy are much more than areas of atrophy that are consistent with previous studies [30,31] they also demonstrate overall whole cortex thickening in patient with migraine compared to control subjects [31]. We find that the cerebellar white matter hypertrophy is more apparent in patient studied accompanied by hypertrophy of cingulate.

Different results have been shown in similar prior research with many areas varying in size, which can be explained by the hypothesis that patients with an aura differ in morphological changes from patients without an aura, as well as the variation in total attack length and attack rates $[\mathbf{5 , 2 6 , 2 7 , 3 0 ]}$. Furthermore, the variable deficits in working memory, executive functions and eye motion control found in different fields of affection $[20,32,33]$ may explain these different areas of affection, and the areas of volume change vary in specific wards depending on the associated symptoms of migraine.

Previous studies [26,27] find an increased cortical thickness of the primary sensorimotor cortex, in our study these areas are hypertrophied in less than one fourth of the patients examined as well as other 
areas such as Nucleus accumabens, Hippocampus and thalamus hypertrophy noted in our study more than frontal areas hypertrophy. Other study shows no abnormality of cortical thickness in migraine patients [28]. These differences in results may be related to patients' symptoms, examined areas and other co-morbidities.

In our study we find medial orbitofrontal gyrus atrophy in many patients as well as posterior superior temporal sulcus, also cerebellar gray matter atrophy is demonstrated in fewer patients, on the other hand the posterior superior temporal sulcus is noted to hypertrophied in other patients with no association to the side of migraine as well. Previous study demonstrated that posterior superior temporal sulcus plays an important role in detecting, predicting, and reasoning about social actions and the intentions underlying action [34]. Other study indicated that it is apart of multisensory convergence zones so it can be linked to migraines changes [35], so that these contradictory volume changes findings require more microstructure study.

In our study, cingulate is hypertrophied in more than half of the patients examined, previous results indicate that anterior cortical cingulate plays an important role in migraine pathogenesis as it is involved in chronic neuropathic pain and its associated anxiety, but its functional modifications in migraine remain unknown [36].

Several studies have examined migraine laterality $[37,38]$ with conflicting results, but right-sided migraine is relative more than left-sided with respect to psychopathology, with also founding predominance among females, while small numbers of studied patients have been found close to the same results.

Our research has several limitations including limited group of patients surveyed, including patients without aura only, further studies on large numbers of patients are recommended.

\section{Conclusion:}

Patients having migraine without aura show gray and white matter volume changes in different cerebral and cerebellar areas that could be detected by MRI and improved by using artificial intelligence software programs for accurate, fast, automated volume changes detection.

\section{Acknowledgment:}

The authors thank NeuroQuant team for their great help by providing us by free access from CORTECHS labs for their NeuroQuant software to do this study on 20 patients, with no financial activities related to the present article.

\section{References}

1- The International Classification of Headache Disorders, 3 rd edition (beta version). Cephalalgia, 33 (9): 629-808, 2013.

2- GRASSINI S. and NORDIN S.: Comorbidity in Migraine with Functional Somatic Syndromes, Psychiatric Disorders and Inflammatory Diseases: A Matter of Central Sensitization? Behav. Med., 43 (2): 91-9, 2017.

3- VOS T., FLAXMAN A.D., NAGHAVI M., et al.: Years lived with disability (YLDs) for 1160 sequelae of 289 diseases and injuries 1990-2010: A systematic analysis for the Global Burden of Disease Study 2010. Lancet, 380 (9859): 2163-96, 2012.

4- FREILINGER T., ANTTILA V., De VRIES B., et al.: Genome-wide association analysis identifies susceptibility loci for migraine without aura. Nat. Genet., 44 (7): 777 82, 2012.

5- JIA Z. and YU S.: Grey matter alterations in migraine: A systematic review and meta-analysis. Neuroimage Clin., 14: 130-40, 2017.

6- LEVY D., STRASSMAN A.M. and BURSTEIN R.: A critical view on the role of migraine triggers in the genesis of migraine pain. Headache, 49 (6): 953-7, 2009.

7- SCHMIDT-WILCKE T., LEINISCH E., STRAUBE A., et al.: Gray matter decrease in patients with chronic tension type headache. Neurology, 65 (9): 1483-6, 2005.

8- DESPOTOVIC I., GOOSSENS B. and PHILIPS W.: MRI segmentation of the human brain: Challenges, methods, and applications. Comput. Math. Methods Med., 2015 450341, 2015.

9- LUNDERVOLD A.S. and LUNDERVOLD A.: An overview of deep learning in medical imaging focusing on MRI. Zeitschrift für Medizinische Physik, 29 (2): 10227, 2019.

10-AZAB M., CARONE M., YING S.H. and YOUSEM D.M.: Mesial Temporal Sclerosis: Accuracy of NeuroQuant versus Neuroradiologist. A.J.N.R. Am. J. Neuroradiol. 36 (8): 1400-6, 2015.

11- CANTO L.N., BOSCA S.C., VICENTE C.A., GILPERONTIN S., PEREZ-MIRALLES F., VILLALBA J.C., NUNEZ L.C. and CASANOVA ESTRUCH B.: Brain Atrophy in Relapsing Optic Neuritis Is Associated With Crion Phenotype. Front. Neurol., 10: 1157, 2019.

12- MEIER R., KNECHT U., LOOSLI T., BAUER S., SLOTBOOM J., WIEST R. and REYES M.: Clinical Evaluation of a Fully-automatic Segmentation Method for Longitudinal Brain Tumor Volumetry. Sci. Rep., 6: 23376, 2016.

13- PERSSON K., BARCA M.L., CAVALLIN L., BRAEKHUS A., KNAPSKOG A.B., SELBAEK G. and ENGEDAL K.: Comparison of automated volumetry of the hippocampus using NeuroQuant(R) and visual assessment of the medial temporal lobe in Alzheimer's disease. Acta Radiol., 59 (8): 997-1001, 2018.

14- ROSS D.E., SEABAUGH J., COOPER L. and SEABAUGH J.: NeuroQuant(R) and NeuroGage(R) reveal 
effects of traumatic brain injury on brain volume. Brain Inj., 32 (11): 1437-41, 2018.

15- SZABO N., FARAGO P., KIRALY A., et al.: Evidence for Plastic Processes in Migraine with Aura: A Diffusion Weighted MRI Study. Front. Neuroanat., 11: 138, 2017.

16- CHONG C.D. and SCHWEDT T.J.: Migraine affects white-matter tract integrity: A diffusion-tensor imaging study. Cephalalgia, 35 (13): 1162-71, 2015.

17-DAI Z., ZHONG J., XIAO P., et al.: Gray matter correlates of migraine and gender effect: A meta-analysis of voxelbased morphometry studies. Neuroscience, 299: 88-96, 2015.

18- ROCCA M.A., CECCARELLI A., FALINI A., et al.: Brain gray matter changes in migraine patients with $\mathrm{T} 2$ visible lesions: A 3-T MRI study. Stroke, 37 (7): 176570, 2006.

19- SCHMIDT-WILCKE T., GANSSBAUER S., NEUNER T., et al.: Subtle grey matter changes between migraine patients and healthy controls. Cephalalgia, 28 (1): 1-4, 2008.

20- SCHMITZ N., ADMIRAAL-BEHLOUL F., ARKINK E.B., et al.: Attack frequency and disease duration as indicators for brain damage in migraine. Headache, 48 (7): 1044-55, 2008.

21- SCHMITZ N., ARKINK E.B., MULDER M., et al.: Frontal lobe structure and executive function in migraine patients. Neurosci. Lett., 440 (2): 92-6, 2008.

22- SCHMIDT-WILCKE T., HIERLMEIER S. and LEINISCH E.: Altered regional brain morphology in patients with chronic facial pain. Headache, 50 (8): 1278-85, 2010.

23- APKARIAN A.V., SOSA Y., SONTY S., et al.: Chronic back pain is associated with decreased prefrontal and thalamic gray matter density. J. Neurosci., 24 (46): 104105, 2004.

24- BURGMER M., GAUBITZ M., KONRAD C., et al.: Decreased gray matter volumes in the cingulo-frontal cortex and the amygdala in patients with fibromyalgia. Psychosom. Med., 71 (5): 566-73, 2009.

25- OBERMANN M., NEBEL K., SCHUMANN C., et al.: Gray matter changes related to chronic posttraumatic headache. Neurology, 73 (12): 978-83, 2009.

26- DaSILVA A.F., GRANZIERA C., SNYDER J., et al.:
Thickening in the somatosensory cortex of patients with migraine. Neurology, 69 (21): 1990-5, 2007.

27- GRANZIERA C., DaSILVA A.F., SNYDER J., et al.: Anatomical alterations of the visual motion processing network in migraine with and without aura. PLoS Med., 3 (10): e402, 2006.

28- DATTA R., DETRE J.A., AGUIRRE G.K., et al.: Absence of changes in cortical thickness in patients with migraine. Cephalalgia, 31 (14): 1452-8, 2011.

29- JOUVENT E., MANGIN J.F., HERVE D., et al.: Cortical folding influences migraine aura symptoms in CADASIL. J. Neurol. Neurosurg. Psychiatry, 83 (2): 213-6, 2012.

30- MALEKI N., BECERRA L., BRAWN J., et al.: Concurrent functional and structural cortical alterations in migraine. Cephalalgia, 32 (8): 607-20, 2012.

31- MESSINA R., ROCCA M.A., COLOMBO B., et al.: Cortical abnormalities in patients with migraine: A surfacebased analysis. Radiology, 268 (1): 170-80, 2013.

32- DITCHFIELD J.A., McKENDRICK A.M. and BADCOCK D.R.: Processing of global form and motion in migraineurs. Vision. Res., 46 (1-2): 141-8, 2006.

33- McKENDRICK A.M. and BADCOCK D.R.: Motion processing deficits in migraine. Cephalalgia, 24 (5): 363 $72,2004$.

34- SHULTZ S., LEE S.M., PELPHREY K., et al.: The posterior superior temporal sulcus is sensitive to the outcome of human and non-human goal-directed actions. Soc. Cogn. Affect. Neurosci., 6 (5): 602-11, 2011.

35- SCHWEDT T.J.: Multisensory integration in migraine. Curr. Opin. Neurol., 26 (3): 248-53, 2013.

36- JIA Z., CHEN X., TANG W., et al.: Atypical functional connectivity between the anterior cingulate cortex and other brain regions in a rat model of recurrent headache. Mol. Pain, 15: 1744806919842483, 2019.

37- LODER E., WEIZENBAUM E. and GIDDON D.: Migraine Pain Location and Measures of Healthcare Use and Distress: An Observational Study. Pain Res. Manag., 6157982, 2018.

38- MYKLAND M.S., BJORK M.H., STJERN M., et al.: Alterations in post-movement beta event related synchronization throughout the migraine cycle: A controlled, longitudinal study. Cephalalgia, 38 (4): 718-29, 2018. 


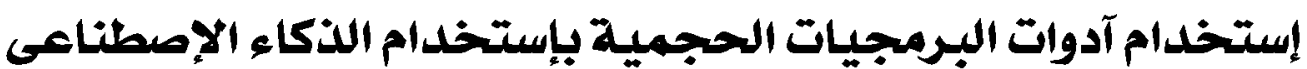

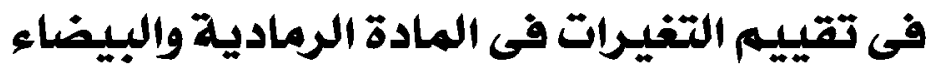

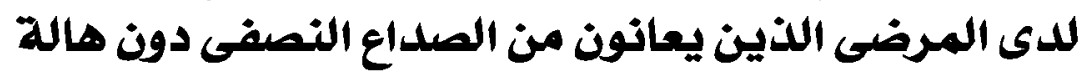

الغرض من هذه الدراسة هوتقييم دود آدوات البرمجيات الحجمية بإستخدام الذكاء الإصطناعى فى تقييم التغيرات فى حجم المادة الرمادية

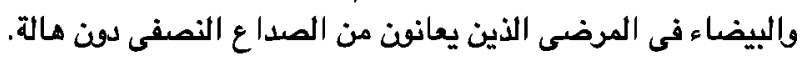

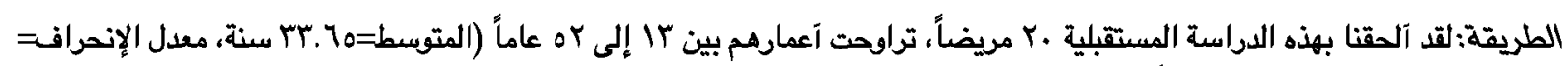

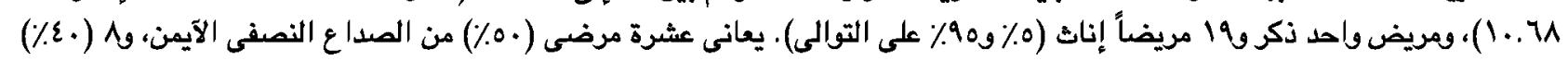

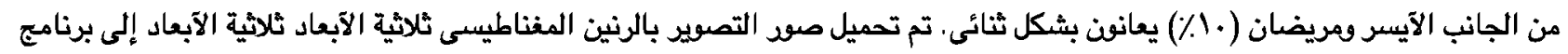
NeuroQuant

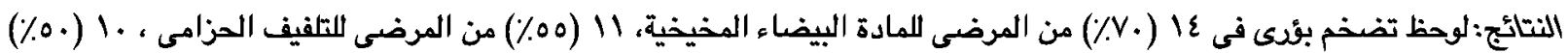

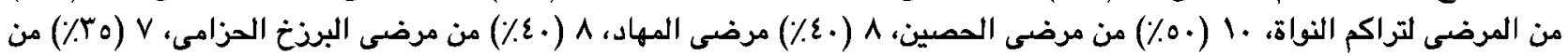

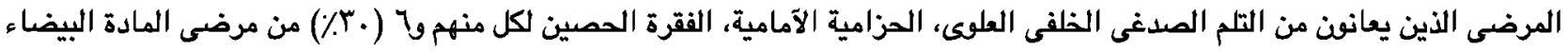

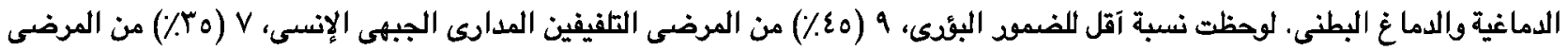

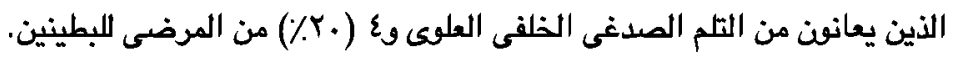

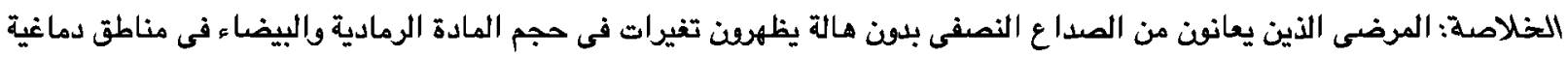

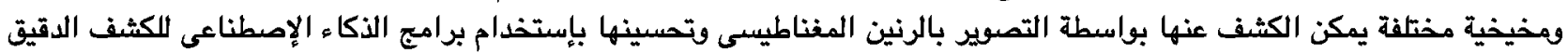
والسريع الآلى لتغييرات العجم. 